\title{
Editorial
}

\section{Tenth Volume of Axioms and Why Axioms Was Launched}

\author{
Shu-Kun Lin (D)
}

check for

updates

Citation: Lin, S.-K. Tenth Volume of Axioms and Why Axioms Was

Launched. Axioms 2021, 10, 129.

https: / / doi.org/10.3390/

axioms10030129

Received: 15 June 2021

Accepted: 18 June 2021

Published: 23 June 2021

Publisher's Note: MDPI stays neutral with regard to jurisdictional claims in published maps and institutional affiliations.
MDPI, St. Alban-Anlage 66, CH-4052 Basel, Switzerland; lin@mdpi.com; Tel.: +41-61-683-77-34

This year we publish the tenth volume of Axioms (ISSN 2075-1680). It has been indexed in Science Citation Index Expanded (SCIE) — Web of Science (Clarivate Analytics) recently in 2021. Our publishing company, MDPI, also marks its 25th anniversary this year. MDPI has over 4000 employees and is the 4th largest publisher of scholarly journals in the world.

Originally, I planned to be a research scientist during my life and wanted to mainly tackle the topics of entropy and symmetry theory. I had published a few papers on those topics about 25 years ago, with the first one being accepted in 1995 and appearing in 1996 [1]. I was preparing myself to set up an axiomatic formula of symmetry, entropy, information, structural stability and process spontaneity, which is similar to the axiomatic system of thermodynamics based on the laws of thermodynamics [2].

However, I could only manage to establish and expand the scholarly publishing project of MDPI and, among many other journals, I launched Entropy (https:/ / www.mdpi.com/ journal/entropy), Symmetry (https://www.mdpi.com/journal/symmetry), Information (https://www.mdpi.com/journal/information) and, of course, Axioms (https://www. mdpi.com/journal/axioms).

Axioms [3] was launched as a journal of mathematical physics and theoretical systems in mathematics, physics and chemistry. Prof. Dr. Angel Garrido was invited to be the founding Editor-in-Chief [3]. Since March 2016, Prof. Dr. Humberto Bustince has been serving as the journal's Editor-in-Chief. We have published 663 articles so far [4].

As with the operation of other MDPI journals [5], we will continue to maintain a fast and rigorous peer review process [6] for Axioms. We hope that you enjoy publishing with us.

Funding: This research received no external funding.

Conflicts of Interest: The author declares no conflict of interest.

\section{References}

1. Lin, S.-K. Correlation of entropy with Similarity and symmetry. J. Chem. Inf. Comput. Sci. 1996, 36, 367-376. [CrossRef]

2. Lin, S.-K. Gibbs Paradox and Similarity Principle. In Bayesian Inference and Maximum Entropy Methods in Science and Engineering, Proceedings of the MaxEnt2008, Boracéia, Brazil, 6-11 July 2008; American Institute Physics: College Park, MD, USA, 2008; Volume 1073, pp. 49-60. [CrossRef]

3. Journal History. Available online: https://www.mdpi.com/journal/axioms/history (accessed on 14 June 2021).

4. Axioms Statistics. Available online: https://www.mdpi.com/journal/axioms/stats (accessed on 14 June 2021).

5. MDPI Journal List. Available online: https://www.mdpi.com/about/journals (accessed on 14 June 2021).

6. List of Publons Reviews for Journals and Conferences. Available online: https://publons.com/ journal (accessed on 14 June 2021). 